\title{
Effect of Age and Magnesium Depletion on Bone Magnesium Pools in Rats
}

\author{
Allen C. Alfrey, Nancy L. Miller, and Richard Trow \\ From the Department of Medicine, Veterans Administration Hospital, and \\ University of Colorado Medical Center, Denver, Colorado 80220
}

A B S T R A C T In vivo and in vitro studies were carried out to characterize the exchangeable bone magnesium pool and determine what effect age and magnesium depletion has on bone magnesium. A highly significant correlation was found between the size of the in vitro elutable and in vivo exchangeable bone magnesium $(r=0.97)$. To show that the exchangeable bone magnesium was the surface-limited bone magnesium, elution studies were performed $4 \mathrm{~h}$ after the in vivo administration of radiomagnesium. Specific activity in the eluant was $85 \%$ of that found in the serum at time of death, suggesting that the elutable and exchangeable bone magnesium pools were largely the same pool.

Bone magnesium concentration fell with increasing age. The entire fall in bone magnesium was a result of a decrease in the surface-limited fraction. Since bone crystals have been shown to enlarge with aging with resulting contraction of the surface area, this would be the most apparent explanation for this finding. During magnesium depletion, magnesium concentration in both the exchangeable and nonexchangeable pools decreased. The fractional change in the exchangeable pool was much larger than the change in total or nonexchangeable bone magnesium, suggesting that the surface-limited magnesium pool is available during magnesium depletion. The change in size of the nonexchangeable bone magnesium pool appeared to be more related to the duration of magnesium depletion than the change in serum magnesium levels. The fall in magnesium concentration in this pool is probably a consequence of continuing formation of low magnesium bone during the depletion period.

\section{INTRODUCTION}

Orent, Kruse, and McCollum in 1932 were able to show that bone magnesium concentration decreases in rats

Received for publication 8 April 1974 and in revised form 24 June 1974. maintained on a magnesium-deficient diet (1). Since that time, numerous studies in a variety of different animal species have confirmed this finding (2-4). However, Heaton (5) and MacIntyre and Davidsson (6) have shown that, although bone magnesium concentration falls, total bone magnesium does not change during magnesium depletion. This finding has prompted a number of investigators to suggest, that bone magnesium concentration falls during magnesium depletion as a consequence of formation of low magnesium bone and that bone magnesium stores are neither available nor utilized during the depletion period. This would seem to explain why bone magnesium has been found to decrease much less in adults as compared to immature animals when both have been placed on a magnesium-deficient diet, since the latter animals would have a more rapid bone formation rate.

In vitro studies using fresh human bone have shown that approximately $30 \%$ of bone magnesium fulfills the criteria for being surface limited, in that it is freely exchangeable and rapidly elutable and it readily equilibrates with the magnesium present in an incubating media (7). It would be expected that this pool should behave similarly in vivo and be available to replace other body deficits during magnesium depletion. In contrast, the larger bone magnesium pool appears to be intimately associated with the apatite crystals and would not be expected to be mobilized during magnesium depletion (7).

The present study was undertaken to characterize further the surface-limited bone magnesium pool in vivo, attempt to determine if this bone pool is the exchangeable bone magnesium, and characterize how age and magnesium depletion affects the compartmentilization of bone magnesium.

\section{METHODS}

Magnesium deficiency was induced in male Sprague-Dawley rats by placing them on a magnesium-deficient diet (ICN Nutritional Biochemicals, Div., International Chemical and 
Nuclear Corp., Cleveland, Ohio) and deionized water. Routine bloods were obtained by tail vein puncture. At the termination of studies, the animals were killed by exsanguination through the abdominal aorta under ether anesthesia.

Bone was obtained from the femur. It was scraped free of adhering tissue, and the marrow was removed with a jet of deionized water. After air drying, the bone was ground in a Wiley mill (Wiley Manufacturing Co., Port Deposit, Md.) to pass through a 20 -mesh screen. This bone was rinsed three times with petroleum ether and further ground to pass through a 60 -mesh screen. A portion of this preparation was used for elution and equilibration studies. A second portion was weighed, dried $16 \mathrm{~h}$ at $130^{\circ} \mathrm{C}$, reweighed, ashed $16 \mathrm{~h}$ at $550^{\circ} \mathrm{C}$, and weighed again. All data are calculated on an ashed weight basis and expressed as mean $\pm 1 \mathrm{SD}$.

Elutions were performed by using $0.15 \mathrm{M} \mathrm{NaCl}$ buffered at $\mathrm{pH} 7.4$ with $0.005 \mathrm{M}$ sodium barbital; $25 \mathrm{mg}$ powdered bone was mixed by mechanical inversion with $3 \mathrm{ml}$ of the buffered solution for $1 \mathrm{~h}$. The supernate was removed after centrifugation and the procedure repeated three additional times with fresh buffer. The total magnesium found in the four supernates is referred to as the elutable bone magnesium pool. Previous studies have shown that only small amounts of magnesium are removed by subsequent elution (7).

Magnesium determinations were performed with a 290B Atomic Absorption Spectrophotometer (Perkin-Elmer, Norwalk, Conn.) operated according to the manufacturer's specifications. Bone ash was dissolved in $0.5 \mathrm{ml} 37 \% \mathrm{HCl}$ and diluted to $5 \mathrm{ml}$ with deionized water before analysis.

Radiomagnesium was obtained from Brookhaven $\mathrm{Na}-$ tional Laboratory, Upton, N. Y., in the form of ${ }^{28} \mathrm{MgCl}_{2}$ $(0.65 \mu \mathrm{Ci} /<1 \mu \mathrm{g}$ stable magnesium). Counting was done in a two-channel deep well scintillation counter. Plasma, erythrocytes, and supernates were diluted to a fixed volume with deionized water. Powdered bone was also counted. Standards having similar geometry were employed.

The exchangeable bone magnesium pool was calculated at 4 and $24 \mathrm{~h}$ by the following formula: $E_{B}=B R / S A$, where $E_{B}=$ exchangeable bone magnesium concentration in milliequivalents per kilogram ash; $\mathrm{BR}={ }^{28} \mathrm{Mg}$ concentration in percent dose per kilogram ash bone; and $\mathrm{SA}=$ plasma $\mathrm{Mg}$ specific activity in percent dose per milliequivalent magnesium at time of death.

\section{RESULTS}

2 -mo-old rats were studied at 2, 4, and $24 \mathrm{~h}$ after the intraperitoneal injection of $8 \mu \mathrm{Ci}$ of ${ }^{28} \mathrm{Mg}$. Serum, bones, and erythrocytes were counted to quantitate radiomagnesium and analyzed to determine stable magnesium content. The ${ }^{28} \mathrm{Mg}$ specific activity in the various tissues at the three time periods are shown in Fig. 1. The in vivo exchangeable bone magnesium was found to be $21 \%$ of the total bone magnesium at $4 \mathrm{~h}$ and $26 \%$ at $24 \mathrm{~h}$.

The elutable bone magnesium was determined by placing bone powder in a magnesium-free barbital buffer for four 1-h elution periods. There was a significant correlation between the size of the elutable and the in vivo exchangeable bone magnesium pools in control and magnesium-deficient animals $(r=0.97) \quad(P<$ 0.001) (Fig. 2). The elutable bone magnesium pool was

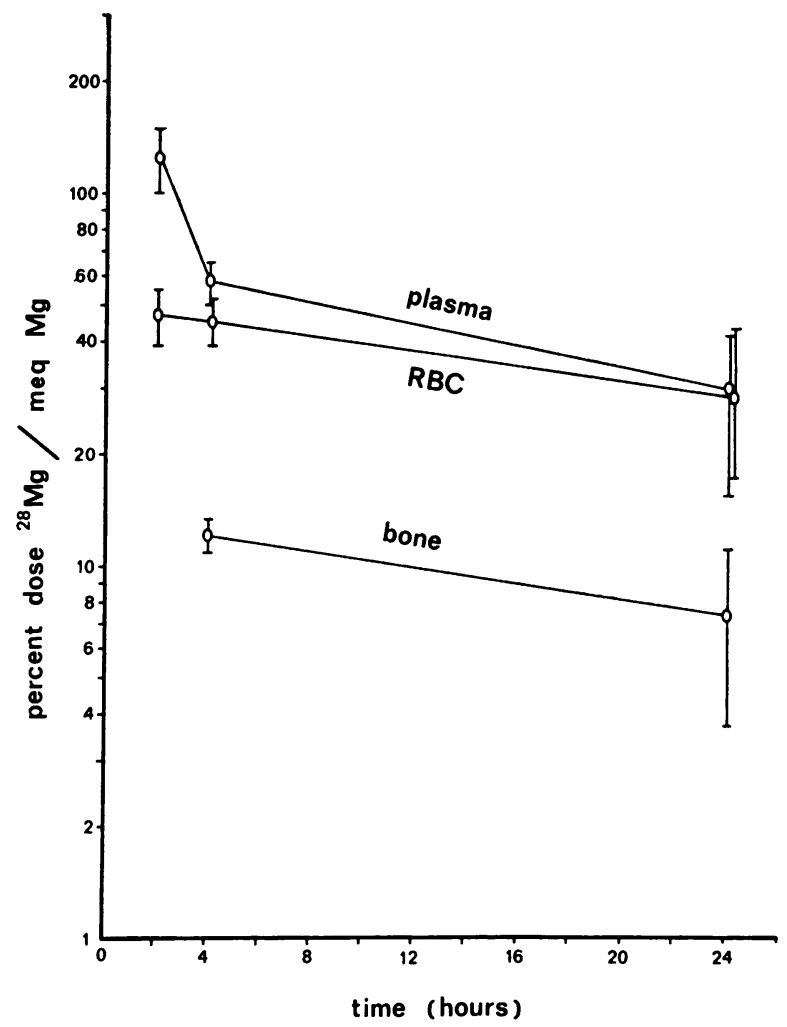

Figure 1 Plasma, erythrocyte and bone specific activity at various study periods after the intraperitoneal injection of ${ }^{28} \mathrm{Mg}$ in control rats. The mean values $\pm 1 \mathrm{SD}$ are shown. $\mathrm{RBC}$ is red blood cells.

found to be approximately $30 \mathrm{meq} / \mathrm{kg}$ ash larger than the exchangeable pool in all bones studied. This probably is a result of the slow dissolution of bone crystals in the elution fluid which produces a systematic base-line error (7). To further characterize the elutable pool, $100 \mathrm{mg}$ of bone powder obtained from animals who had received ${ }^{28} \mathrm{Mg} 4 \mathrm{~h}$ before death were equilibrated in $4 \mathrm{ml}$ magnesium-free buffer. The ${ }^{28} \mathrm{Mg}$ specific activity in the eluant was found to be $85 \%$ of the 4 -h serum specific activity.

The in vitro exchangeable pool was determined by equilibrating $25 \mathrm{mg}$ of bone overnight in $3 \mathrm{ml}$ buffer adjusted to contain $80-85 \%$ of the magnesium found in the serum. After the addition of $2 \mu \mathrm{Ci}{ }^{28} \mathrm{Mg}$, the bone was equilibrated 4 more $\mathrm{h}$ and the supernate withdrawn for counting. The bone was then eluted four times with 3 $\mathrm{ml}$ magnesium-free buffer and stable magnesium measured in the supernate. This elutable pool correlated well with the in vitro exchangeable pool $(r=0.99)(P<$ 0.001 ) (Fig. 3).

Effect of age on bone magnesium. Total bone and elutable bone magnesium was measured in weanling, 


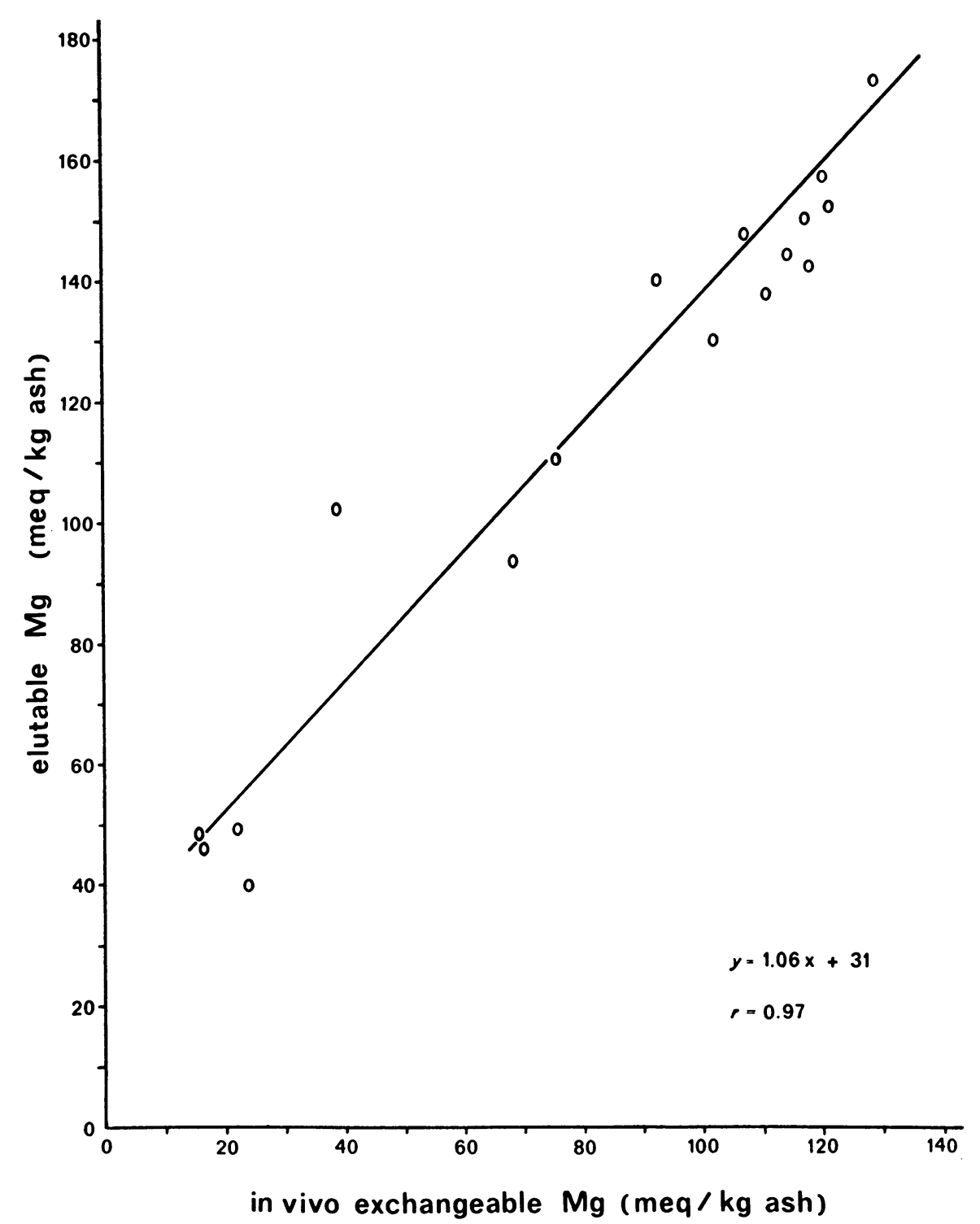

FIGURE 2 Correlation between the size of the in vitro elutable magnesium pool and in vivo exchangeable magnesium pool in control and magnesium-deficient animals.

2-mo-old, and 5-7-mo-old animals. Total bone magnesium was significantly less in the older animals when compared to either the weanlings $(P<0.001)$ or 2 -mo-old animals $(P<0.001)$ (Table I). The elutable bone magnesium was found to decrease with age and was significantly different between all groups $(P<0.001)$. Since the nonelutable bone magnesium was not significantly different in the three groups, the entire decrease in bone magnesium with age was accounted for by a fall in the elutable or surface-limited bone magnesium pool (Table I). In contrast to bone magnesium, plasma magnesium values in the three groups of animals were not significantly different.
Effect of magnesium depletion on bone magnesium. Serum and bone magnesium levels found in 2-mo-old control animals and rats maintained on a magnesiumdeficient diet for 3 and 43 days, respectively, are shown in Table II. By the third day on a magnesium-deficient diet there was a significant fall in plasma magnesium. The total bone magnesium concentration was decreased by $15 \%$. This fall in bone magnesium concentration war largely accounted for by a reduction in the surfacelimited magnesium pool, which had decreased by $27 \%$ as measured by the elution technique. At the same time period, the nonelutable bone magnesium had decreased by only $10 \%$. 


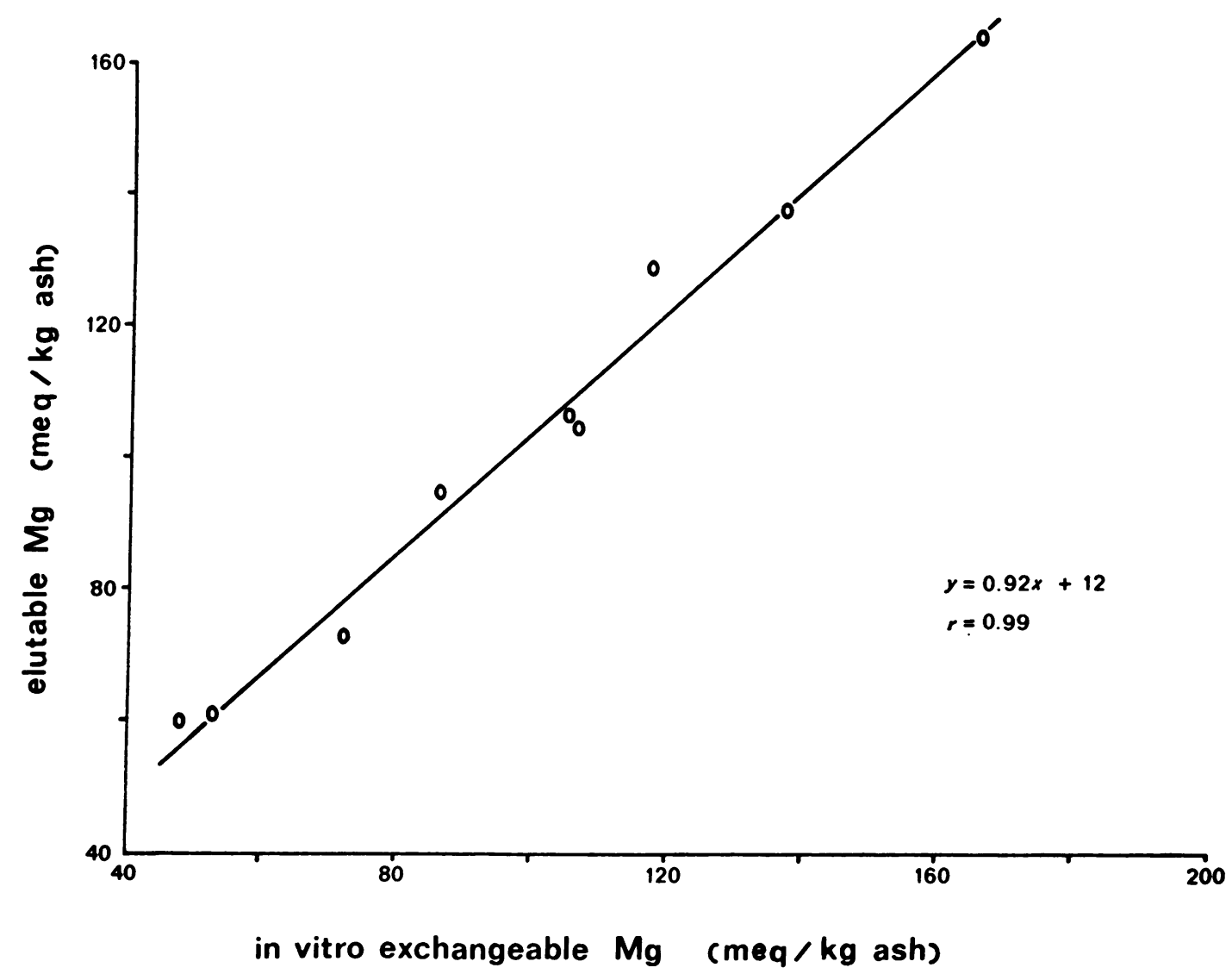

FIgURE 3 Correlation between the size of the in vitro exchangeable and elutable magnesium pools in controls and magnesium-deficient animals.

After 43 days on a magnesium-deficient diet, the magnesium concentration in the elutable pool had been reduced by $71 \%$ (Table II). During this same time period, the magnesium concentration in the nonelutable pool was reduced by approximately one-half this amount $(35 \%)$.

To characterize further the effect of magnesium depletion on the surface-limited magnesium pool, the 3-day and 43-day deficient animals were given ${ }^{28} \mathrm{Mg}$ intraperi-

TABLE I

Effect of Age on Bone Magnesium

\begin{tabular}{|c|c|c|c|c|}
\hline & $\begin{array}{l}\text { Total } \\
\text { bone }\end{array}$ & Residual & Elutable & Plasma \\
\hline & \multicolumn{2}{|c|}{$m e q / k g$ ash } & \multicolumn{2}{|c|}{ meq/liter } \\
\hline Weanlings & $623 \pm 22$ & $435 \pm 29$ & $188 \pm 9$ & $1.40 \pm 0.02$ \\
\hline 2-mo old & $593 \pm 27$ & $439 \pm 28$ & $153 \pm 9$ & $1.59 \pm 0.16$ \\
\hline 5-7-mo old & $530 \pm 19$ & $447 \pm 15$ & $82 \pm 6$ & $1.50 \pm 0.29$ \\
\hline \multicolumn{5}{|l|}{$P$ values } \\
\hline Weanling vs. 2 mo & NS & NS & $<0.001$ & NS \\
\hline Weanling vs. 5-7 mo & $<0.001$ & NS & $<0.001$ & NS \\
\hline 2 mo vs. $5-7 \mathrm{mo}$ & $<0.001$ & NS & $<0.001$ & NS \\
\hline
\end{tabular}

toneally. The animals were killed $4 \mathrm{~h}$ after the injection, and serum and bone were counted for radiomagnesium and analyzed for stable magnesium. The $4 \mathrm{~h}$ serum ${ }^{28} \mathrm{Mg}$ specific activity was significantly higher in the 3-day deficient group $(P<0.01)$ and 43-day deficient group $(P<0.001$ ) when compared to the control group (Table III). Bone ${ }^{28} \mathrm{Mg}$ (percent dose) was significantly lower in the 43-day deficient animals when compared to either the control or 3 -day deficient animals $(P<0.001)$ (Ta-

TABLE II

Effect of Magnesium Depletion on Bone Magnesium

\begin{tabular}{|c|c|c|c|c|}
\hline & $\begin{array}{l}\text { Total } \\
\text { bone }\end{array}$ & Residual & Elutable & Plasma \\
\hline & & meq/kg ash & & meq/liter \\
\hline Control & $593 \pm 27$ & $439 \pm 28$ & $153 \pm 9$ & $1.59 \pm 0.16$ \\
\hline 3-day deficient & $506 \pm 13.4$ & $395 \pm 20.5$ & $111 \pm 20$ & $0.94 \pm 0.42$ \\
\hline 43-day deficient & $331 \pm 21$ & $286 \pm 18.7$ & $45 \pm 3.2$ & $0.53 \pm 0.09$ \\
\hline \multicolumn{5}{|l|}{$P$ values } \\
\hline Control vs. 3 day & $<0.001$ & $<0.025$ & $<0.005$ & $<0.01$ \\
\hline Control vs. 43 day & $<0.001$ & $<0.001$ & $<0.001$ & $<0.001$ \\
\hline 3 day vs. 43 day & $<0.001$ & $<0.001$ & $<0.001$ & $<0.001$ \\
\hline
\end{tabular}


TABLE III

Radiomagnesium Studies

\begin{tabular}{|c|c|c|c|c|c|}
\hline & Serum & Bone & \multicolumn{2}{|c|}{ Exchangeable } & Nonexchangeable \\
\hline & $\begin{array}{c}{ }^{28} \mathrm{Mg} \% \\
\text { dose/meq } \mathrm{Mg}\end{array}$ & $\begin{array}{c}{ }^{28} \mathrm{Mg} \% \\
\text { dose/meq Mg }\end{array}$ & $\%$ total bone $M g$ & $\mathrm{meq} / \mathrm{kg}$ ash & $m e q / k g$ ash \\
\hline Controls & $57.4 \pm 7.7$ & $11.8 \pm 1.6$ & $20.6 \pm 1.14$ & $120 \pm 8.3$ & $462 \pm 14.8$ \\
\hline 3-day deficient & $91.8 \pm 16.1$ & $12.2 \pm 4.1$ & $13.7 \pm 4.2$ & $70 \pm 23$ & $438 \pm 13.5$ \\
\hline 43-day deficient & $97.2 \pm 21.6$ & $5.64 \pm 1.1$ & $6.0 \pm 1.55$ & $20 \pm 3.9$ & $311 \pm 24.5$ \\
\hline \multicolumn{6}{|l|}{$P$ values } \\
\hline Controls vs. 3 day & $<0.01$ & NS & $<0.025$ & $<0.005$ & $<0.005$ \\
\hline Controls vs. 43 day & $<0.001$ & $<0.001$ & $<0.001$ & $<0.001$ & $<0.001$ \\
\hline 3 day vs. 43 day & NS & $<0.001$ & $<0.0025$ & $<0.005$ & $<0.001$ \\
\hline
\end{tabular}

Values are mean $\pm \mathrm{SD}$ at $4 \mathrm{~h}$.

ble III). The exchangeable bone magnesium had fallen from $20.6 \%$ of the total bone magnesium in the control animals to $13.7 \%$ by the $3 \mathrm{rd}$ day and $6 \%$ by the $43 \mathrm{rd}$ day on a deficient diet. The net loss of magnesium from the exchangeable pool was also greater than the loss of magnesium from the nonexchangeable pool $(50 \mathrm{meq} / \mathrm{kg} /$ ash as compared to $24 \mathrm{meq} / \mathrm{kg} / \mathrm{ash}$ ) in the 3 -day deficient animals (Table III).

Total bone magnesium was estimated by removing and weighing the entire skeleton from two control and two magnesium-deficient animals by the method of Subrahmanyan, Duckworth, and Godden (8). It was assumed

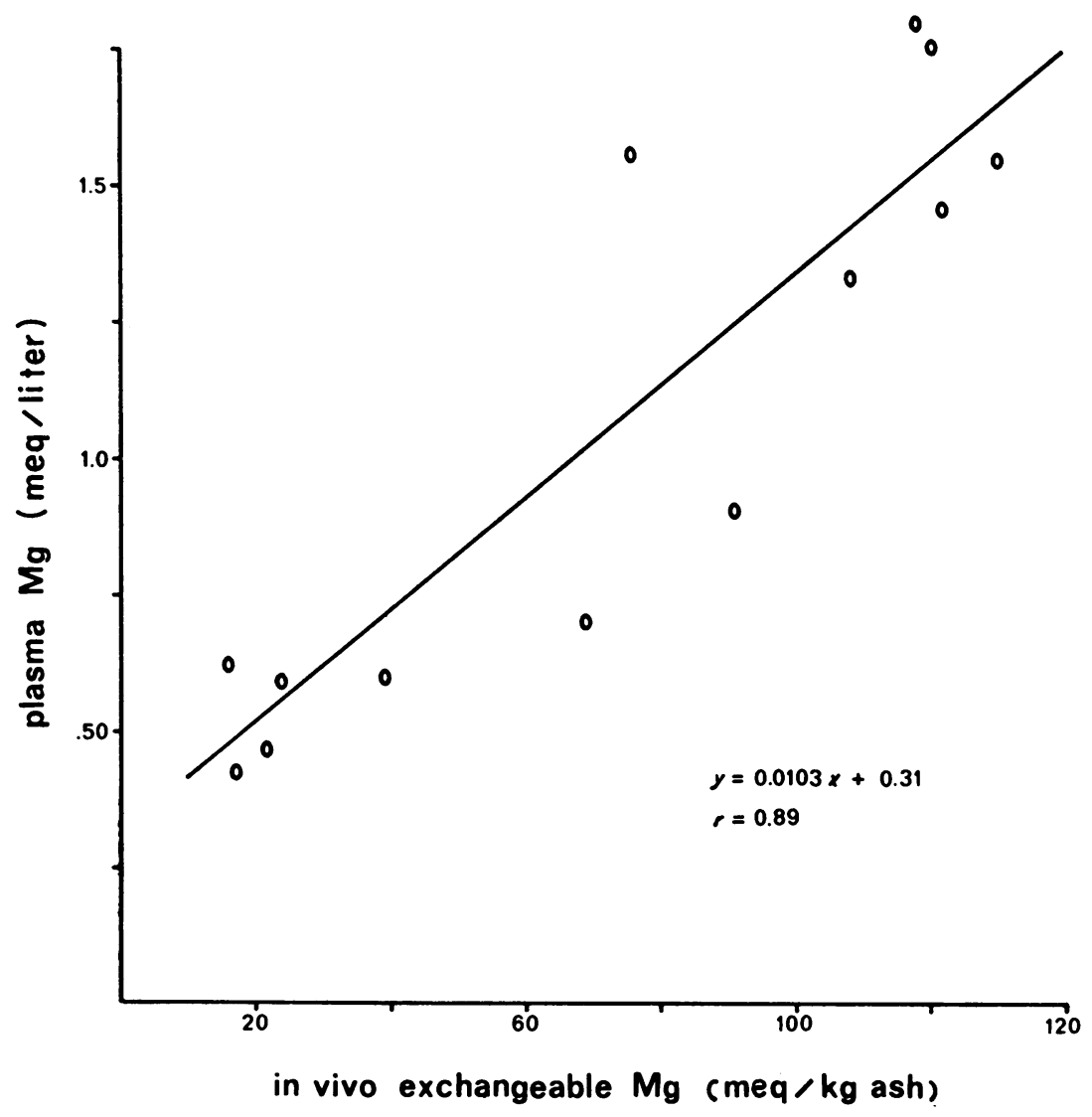

FIGURE 4 Correlation between the size of the in vivo exchangeable magnesium pool and plasma magnesium levels in control and magnesium-deficient animals. 


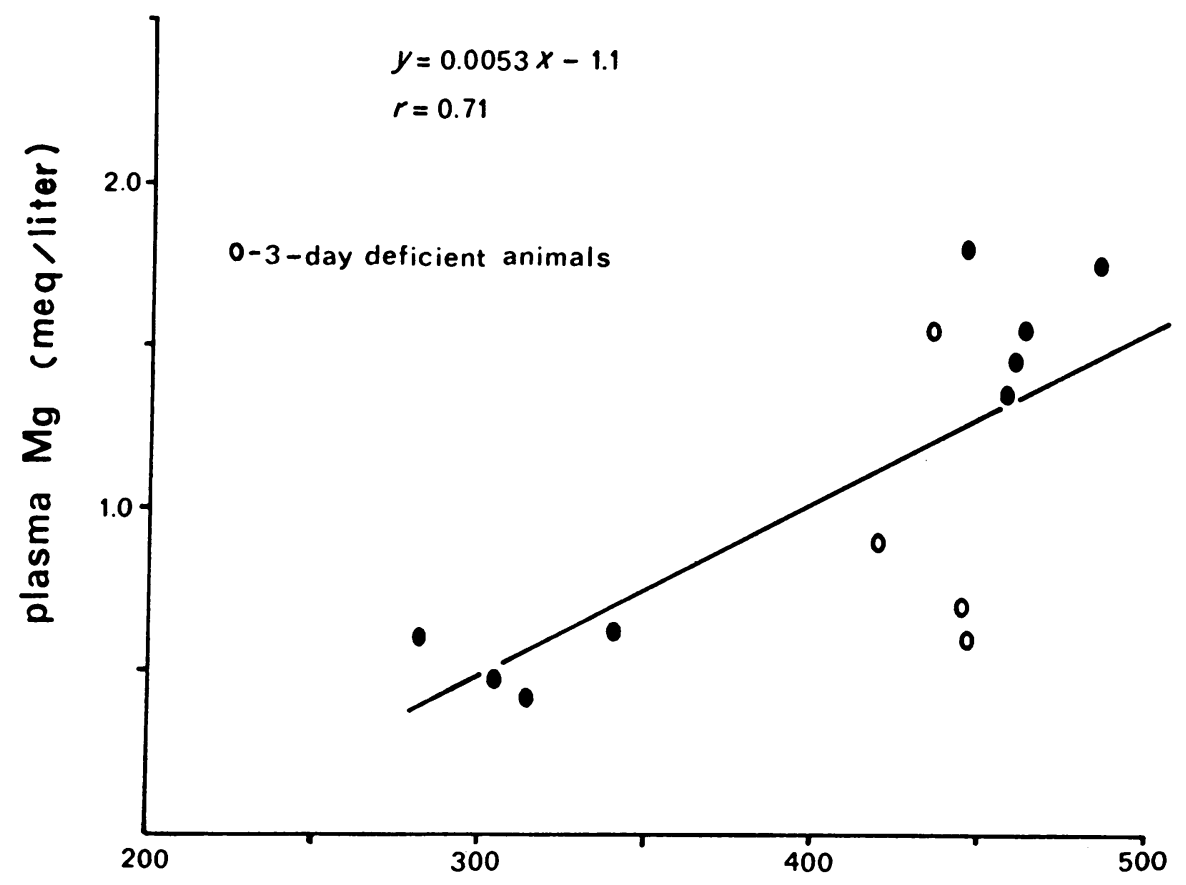

in vivo nonexchangeable $\mathrm{Mg}$ ( $\mathrm{meq} / \mathrm{kg}$ ash)

FIGURE 5 Correlation between the size of the in vivo nonexchangeable bone magnesium and plasma magnesium levels in control and deficient animals. The open circles (O) represent the 3-day deficient animals and closed circles (๑) the control and 43-day deficient animals.

that the exchangeable magnesium should be relatively constant throughout the skeleton. The total bone exchangeable magnesium was calculated to be 0.374 meq in the control animals, $0.18 \mathrm{meq}$ in the 3 -day deficient animals, and $0.062 \mathrm{meq}$ in the 43-day deficient animals.

The size of the in vivo exchangeable pool and nonexchangeable bone magnesium pool were each correlated with the serum magnesium levels in the three study groups. There was a highly significant correlation between the exchangeable bone magnesium pool and plasma magnesium levels (Fig. 4$)(r=0.89) \quad(P<$ $0.001)$. Although there was a correlation between the size of the nonexchangeable pool and plasma magnesium levels (Fig. 5) $(r=0.71)(P<0.01)$, it was less than the above correlation. This lack of a close correlation is especially apparent in the three 3-day deficient animals who had hypomagnesemia and in whom the serum magnesium was disproportionately low in relation to the nonexchangeable bone magnesium pool (Fig. 5).

To determine the effect of magnesium depletion on bone magnesium in different age groups, weanlings and 5-7-mo-old rats were placed on a magnesium-deficient diet. The results are shown in Table IV. In the 5-7-moold animals there was no significant change in total bone or elutable bone magnesium by the eighth day of depletion. In contrast, at the same time period, total bone magnesium concentration was reduced by $37 \%$ and elutable magnesium by $46 \%$ in the weanlings. The weanlings experienced a $31 \%$ weight gain, whereas the 5-7-mo-old animals had a $6 \%$ decrease in body weight during the 8-day study period. Thus, the increase soft tissue demand for magnesium might have been an additional factor responsible for the rapid loss of bone magnesium in the former group of animals. By the 21 st day on a magnesium-deficient diet, the elutable bone magnesium concentration had fallen by $21 \%$ and total bone magnesium by $12 \%$ in the $5-7$-mo-old animals.

TABLE IV

Effect of Age on Bone Magnesium during Depletion

\begin{tabular}{lcclc}
\hline & Total & Residual & Elutable & Serum \\
\hline Weanlings & & meq/kg ash & & meq/liter \\
$\quad$ Control & $623 \pm 22$ & $435 \pm 29$ & $188 \pm 9$ & $1.38 \pm 0.02$ \\
8-day deficient & $392 \pm 20$ & $291 \pm 15$ & $101 \pm 12$ & $0.54 \pm 0.15$ \\
5-7-mo old & & & & \\
$\quad$ Control & $530 \pm 19$ & $447 \pm 15$ & $82 \pm 6$ & $1.50 \pm 0.29$ \\
21-day deficient & $466 \pm 10$ & $400 \pm 12$ & $65 \pm 12$ & $0.33 \pm 0.07$ \\
\hline
\end{tabular}




\section{DISCUSSION}

Studies carried out by Neuman and Mulryan (9) on synthetic apatte would suggest that bone magnesium is largely a surface-limited ion. If this were the case, bone magnesium should be freely exchangeable and readily available during magnesium depletion. However, studies using radiomagnesium have shown that only a small fraction of bone magnesium is exchangeable (10, 11), and in vitro studies performed on fresh human bone have shown that only $30 \%$ of total bone magnesium is surface limited (7). In the present study, surface-limited magnesium was measured in vivo and in vitro by radiomagnesium and elution techniques. Approximately $21 \%$ of the bone magnesium was found to be freely exchangeable with radiomagnesium and readily elutable. A highly significant correlation was found between the size of the in vitro elutable magnesium pool and in vivo exchangeable bone magnesium pool. Additional evidence for the elutable pool being the in vivo exchangeable pool was obtained by performing elution studies on bones from animals who had received radiomagnesium $4 \mathrm{~h}$ before death. The ${ }^{28} \mathrm{Mg}$ specific activity in the eluant was found to be $85 \%$ of the 4-h plasma specific activity in these animals. Since the ${ }^{28} \mathrm{Mg}$ specific activity of this pool was similar to the 4-h plasma specific activity it would appear that the elutable bone magnesium pool comes into almost complete equilibration with the serum magnesium pool within this time period. It can thus be concluded that the surface-limited magnesium is the exchangeable bone magnesium, and the size of this pool can be accurately estimated by elution techniques.

Total bone magnesium was found to decrease with age. This entire fall in bone magnesium was a result of a reduction in size of the surface-limited magnesium pool. Breibart, Lee, McCoord, and Forbes also showed that the exchangeable bone magnesium pool was smaller in older, as compared to younger, animals (10). Since the plasma magnesium was not different in the various age groups, the most likely reason for the above finding is a change in bone crystal size with age. Robinson and Watson have shown that newly formed bone has a smaller crystal size, larger surface area, and probably larger hydration shell than older bones (11).

By definition, a surface-limited ion on bone should be rapidly exchangeable and readily elutable, and should equilibrate with the concentration of the ion in a bathing media. Therefore, the size of this bone magnesium pool should be determined by the plasma magnesium level. A highly significant correlation between the size of the surface-limited magnesium, as measured by the elution technique, and radiomagnesium exchange and plasma magnesium level was found. Evidence that this pool is rapidly available during magnesium depletion is the finding in 2-mo-old rats that the exchangeable mag- nesium pool had fallen by $43 \%$ after only 3 days on a magnesium-deficient diet. It seems highly unlikely that the change in concentration of magnesium in the surfacelimited pool could be accounted for by bone formation during the 3-day magnesium depletion period, in view of the large change in concentration, short duration of magnesium depletion, and the fact that both the fraction change ( 0.42 vs. 0.05 ) and net loss ( 50 vs. $24 \mathrm{meq} /$ $\mathrm{kg}$ ash) were much greater from the exchangeable than the nonexchangeable bone magnesium pool or total bone magnesium. Only a limited number of radiomagnesium studies have been carried out in magnesium-deficient animals $(12,13)$. Field and Smith did find that the exchangeable bone magnesium was similar in control and deficient animals (12). However, in their studies, a large stable magnesium carrier ( $1 \mathrm{mg}$ ) was used which normalized the plasma magnesium levels in the deficient animals and could have increased the size of the surface-limited or exchangeable bone magnesium pool.

Although the net loss was usually greater, the fractional change in nonexchangeable bone magnesium was consistently less than the surface-limited magnesium in all groups of magnesium-deficient animals at all time periods. In contrast to the exchangeable bone magnesium pool, the fraction of total bone magnesium contributed to by the nonelutable pool actually rose from $79 \%$ of the total bone magnesium in control animals to $94 \%$ of total bone magnesium in deficient animals. There was a correlation between plasma magnesium and nonexchangeable bone magnesium, however, this correlation was less significant than that found between the exchangeable magnesium and plasma magnesium. The nonexchangeable bone magnesium appeared to be influenced more by the duration of magnesium depletion than the serum magnesium level.

Earlier studies have shown that the nonexchangeable magnesium pool is intimately associated with the apatite crystal (7). In turn, its release and deposition would be dependent on bone resorptive and formation processes. The most likely explanation for the fall in magnesium concentration in this pool would appear to be continuing bone formation during the magnesium depletion period. This would also explain why the fall was much greater in small animals who would be expected to have more rapid bone formation rates. Since the solid reflects the liquid from which it is formed, it would appear that the serum magnesium level would determine the amount of magnesium deposited with crystal formation and in turn the size of the nonexchangeable bone magnesium pool. This would also explain why this pool size does not change with age, since serum magnesium is constant.

\section{ACKNOWLEDGMENTS}

This study was supported by Veterans Administration General Research Funding. 
The authors are grateful to Ms. Dottie Goodman for secretarial help in preparing the manuscript.

\section{REFERENCES}

1. Orent, E. R., H. D. Kruse, and E. V. McCollum. 1932. Studies on magnesium deficiency in animals. II. Species variation in symptomatology of $\mathrm{Mg}$ deprivation. Am. J. Physiol. 101: 454-461.

2. Smith, R. H. 1959. Calcium and magnesium metabolism in calves. IV. Bone composition in magnesium deficiency and the control of plasma magnesium. Biochem. J. 71 : 609-614.

3. Martindale, L., and F. W. Heaton. 1964. Magnesium deficiency in the adult rat. Biochem. J. 92: 119-126.

4. Reddy, C. R., J. W. Coburn, D. L. Hartenbower, R. M. Friedler, A. S. Brickman, S. G. Massry, and J. Jowsey. 1973. Studies on mechanisms of hypocalcemia of magnesium depletion. J. Clin. Invest. 52: 3000-3010.

5. Heaton, F. W. 1965. The parathyroid glands and magnesium metabolism in the rat. Clin. Sci. 28: 543-553.

6. MacIntyre, I., and D. Davidsson. 1958. The production of secondary potassium depletion, sodium retension, nephrocalcinosis and hypercalcaemia by magnesium deficiency. Biochem. J. 70: 456-462.

7. Alfrey, A. C., and N. L. Miller. 1973. Bone magnesium pools in uremia. J. Clin. Invest. 52: 3019-3027.

8. Subrahmanyan, V., J. Duckworth, and W. Godden. 1939. CLXXIV. The quantitative separation of the skeleton of small animals. Biochem. J. 33: 1421-1424.

9. Neuman, W. F., and F. J. Mulryan. 1971. Synthetic hydroxyapatite crystals. IV. Magnesium incorporation. Calcif. Tissue Res. 7: 133-138.

10. Breibart, S., J. S. Lee, A. McCoord, and G. B. Forbes. 1960. Relation of age to radiomagnesium exchange in bone. Proc. Soc. Exp. Biol. Med. 105: 361-363.

11. Robinson, R. A., and M. L. Watson. 1955. Crystalcollagen relationships in bone as observed in the electron microscope. III. Crystal and collagen morphology as a function of age. Ann. N. Y. Acad. Sci. 60: 596-628.

12. Field, A. C., and B. S. W. Smith. 1964. Effect of magnesium deficiency on the uptake of ${ }^{28} \mathrm{Mg}$ by the tissues in mature rats. Br. J. Nutr. 18: 103-113.

13. McAleese, D. M., M. C. Bell, and R. M. Forbes. 1961. Magnesium studies in lambs. J. Nutr. $74: 505-514$. 